\title{
Adhesion molecules in vernal keratoconjunctivitis
}

\author{
Ahmed M Abu El-Asrar, Karel Geboes, Soliman Al-Kharashi, Khalid F Tabbara, \\ Luc Missotten, Valeer Desmet
}

Department of Ophthalmology, College of Medicine, King Saud University, Riyadh, Saudi Arabia

A M Abu El-Asrar S Al-Kharashi

K F Tabbara

\section{Laboratory of} Histochemistry and Cytochemistry, University Hospital, St Rafael, Leuven, Belgium

K Geboes

V Desmet

Department of Ophthalmology, St Rafael, Leuven, Belgium

L Missotten

Correspondence to: Dr Ahmed M Abu El-Asrar, Department of

Ophthalmology, King

Abdulaziz University Box 245, Riyadh 11411, Saudi Arabia.

Accepted for publication 25 June 1997 University Hospital,

Hospital, Airport Road, PO

\begin{abstract}
Aims/background-Adhesion molecules play a key role in the selective recruitment of different leucocyte population to inflammatory sites. The purpose of the present study was to investigate the presence and distribution of adhesion molecules in the conjunctiva of patients with vernal keratoconjunctivitis (VKC).

Methods-The presence and distribution of adhesion molecules were studied in 14 conjunctival biopsy specimens from seven patients with active VKC and in four normal conjunctival biopsy specimens. We used a panel of specific monoclonal antibodies (mAbs) directed against intercellular adhesion molecule-1 (ICAM-1), intercellular adhesion molecule-3 (ICAM3), lymphocyte function associated antigen-1 (LFA-1), very late activation antigen-4 (VLA-4), vascular cell adhesion molecule-1 (VCAM-1), and endothelial leucocyte adhesion molecule-1 (ELAM1). In addition, a panel of $\mathrm{mAbs}$ were used to characterise the composition of the inflammatory infiltrate.

Results-In the normal conjunctiva, ICAM-1 was expressed on the vascular endothelium only, LFA-1 and ICAM-3 on epithelial and stromal mononuclear cells , and VLA-4 on stromal mononuclear cells. The expression of VCAM-1 and ELAM-1 was absent. The number of cells expressing adhesion molecules was found to be markedly increased in all VKC specimens. This was concurrent with a heavy inflammatory infiltrate. Strong ICAM-1 expression was induced on the basal epithelial cells, and vascular endothelial cells. Furthermore, ICAM-1 was expressed on stro-
\end{abstract}

Table 1 Monoclonal antibodies used in this study

\begin{tabular}{llll}
\hline Antibody (clone) & Specificity & Working dilution & Source* \\
\hline CD 49 D & VLA-4 $\alpha$ chain & $1: 20$ & Dakopatts \\
CD 11a & LFA-1 $\alpha$ chain & $1: 20$ & Dakopatts \\
CD 18 & LFA-1 $\beta$ chain & $1: 20$ & Dakopatts \\
CD 54 & ICAM-1 & $1: 20$ & Dakopatts \\
CD 50 & ICAM-3 & $1: 20$ & Dakopatts \\
CD 106 & VCAM-1 & $1: 10$ & Dakopatts \\
CD 62 E & E-selectin (ELAM-1) & $1: 100$ & Dakopatts \\
HLA-DR & MHC class II antigens & $1: 50$ & Becton-Dickinson \\
OKT4 & T helper/inducer cells & $1: 20$ & Ortho Diagnostics \\
Leu 3a & T helper/inducer cells & $1: 5$ & Becton-Dickinson \\
OKT8 & T cytotoxic/suppressor cells & $1: 10$ & Ortho Diagnostics \\
L26 & Pan B cells & $1: 100$ & Dakopatts \\
KP1 & Macrophages & $1: 50$ & Dakopatts \\
\hline
\end{tabular}

*Location of manufacturers: Dakopatts A/S, Copenhagen, Denmark; Becton-Dickinson, Sunnyvale, CA, USA; Ortho Diagnostics, Raritan, NJ, USA.

VLA-4 = very late activation antigen- 4 ; LFA-1 = lymphocyte function associated antigen-1; ICAM-1 = intercellular adhesion molecule-1; ICAM-3 = intercellular adhesion molecule-3, VCAM-1 = vascular cell adhesion molecule-1; ELAM-1 = endothelial leucocyte adhesion molecule-1; MHC = major histocompatibility complex

OKT4 and Leu3a were applied simultaneously. mal mononuclear cells. LFA-1 and ICAM-3 were expressed on the majority of epithelial and stromal infiltrating mononuclear cells. VLA-4 expression was noted on stromal mononuclear cells. Compared with controls, VKC specimens showed significantly more ICAM-3 ${ }^{+}$, LFA-1 ${ }^{+}$, and VLA-4 ${ }^{+}$cells. VCAM- 1 and ELAM-1 were induced on the vascular endothelial cells. Conclusions-Increased expression of adhesion molecules may play an important role in the pathogenesis of VKC.

(Br f Ophthalmol 1997;81:1099-1106)

Vernal keratoconjunctivitis (VKC) is a chronic, seasonally exacerbated bilateral external allergic ocular inflammation. In previous immunohistochemical studies, we have demonstrateda complex immunopathogenesis of thedisease. Distinct components involved inIgE mediated immune mechanisms, as well as humoral and cell mediated immune reactions, were detected in the conjunctival tissue of patients with VKC. The inflammatory infiltrate in the conjunctival tissue in patients with active VKC was composed of eosinophils, mast cells showing membranous IgE staining, B lymphocytes, $\mathrm{IgA}^{+}, \mathrm{IgG}^{+}, \mathrm{IgM}^{+}$, and $\operatorname{IgE}^{+}$plasma cells, $\mathrm{T}$ lymphocytes, macrophages, dendriticcells, and dendritic cells bearing IgE. ${ }^{2}$

The molecular basis for the selective migration and accumulation of the different inflammatory cells observed in VKC has not yet been defined. Recently, it has been shown that leucocyte adhesion is a mandatory event in the pathogenesis of an inflammatory response. Leucocytes must adhere to the endothelium in order to migrate to the inflammatory focus. Lymphocytes must also adhere to antigen presenting cells, and antigen bearing target cellsso that normal immunological responsescan occur. Adhesion is regulated by adhesion molecules on circulating leucocytes, and these molecules bind to their ligands on vascular endothelial cells and on target cells. ${ }^{3}$

The cell adhesion molecules are classified into three major families: (a) the integrins, (b) the immunoglobulin gene superfamily, and (c) the selectins. Integrins are heterodimers consisting of non-covalently linked $\alpha$ and $\beta$ subunits with an extracellular ligand binding site and an intracellular portion linked to the cytoskeleton. This group is subdivided into various families according to the associated $\beta$ subunit. Very late activation antigen-4 (VLA-4) is a $\beta 1$ integrin. Lymphocyte function associated antigen-1 (LFA-1) is a $\beta 2$ integrin. Members of the immunoglobulin gene superfamily 


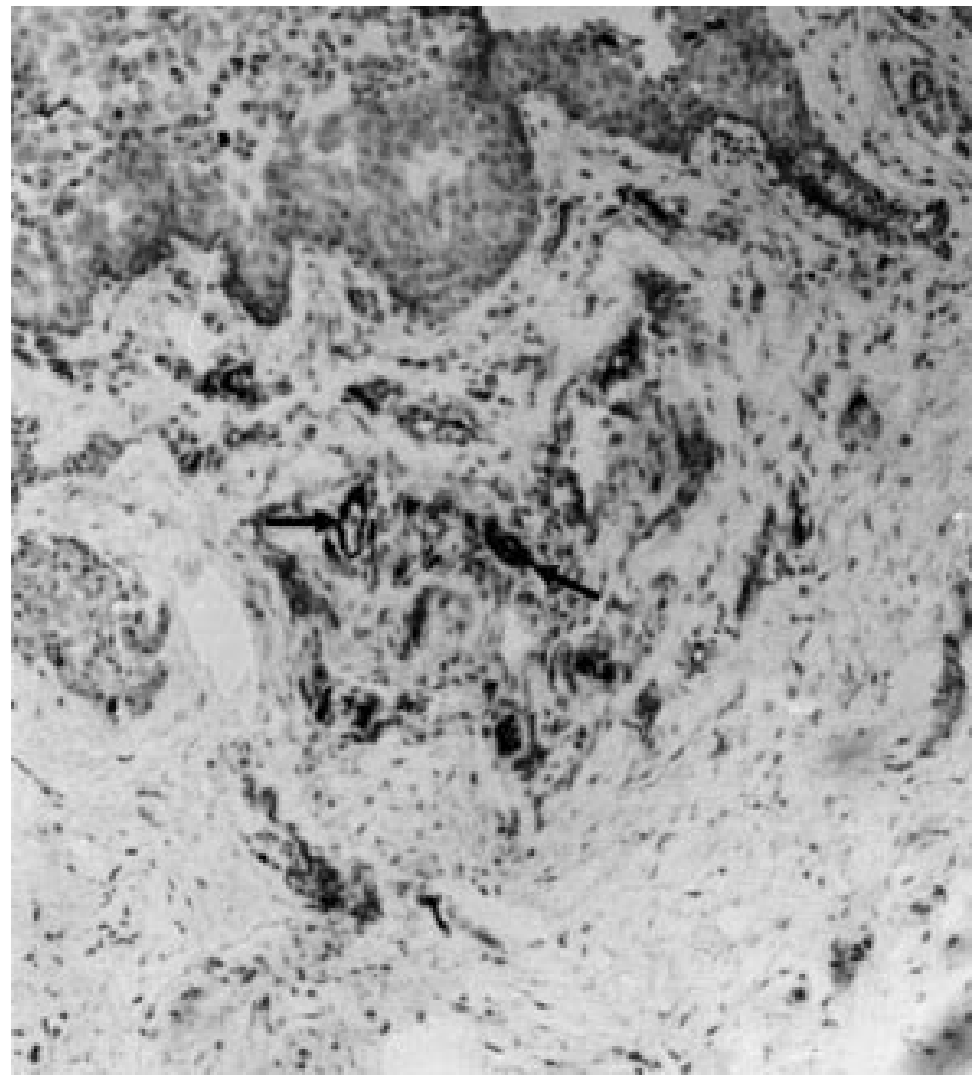

Figure 1 Normal conjunctiva. Immunohistochemical staining for intercellular adhesion molecule-1 (ICAM-1). ICAM-1 is expressed on the vascular endothelium only (arrows) (three step avidin/biotin peroxidase labelled complex procedure; $\times 200)$.

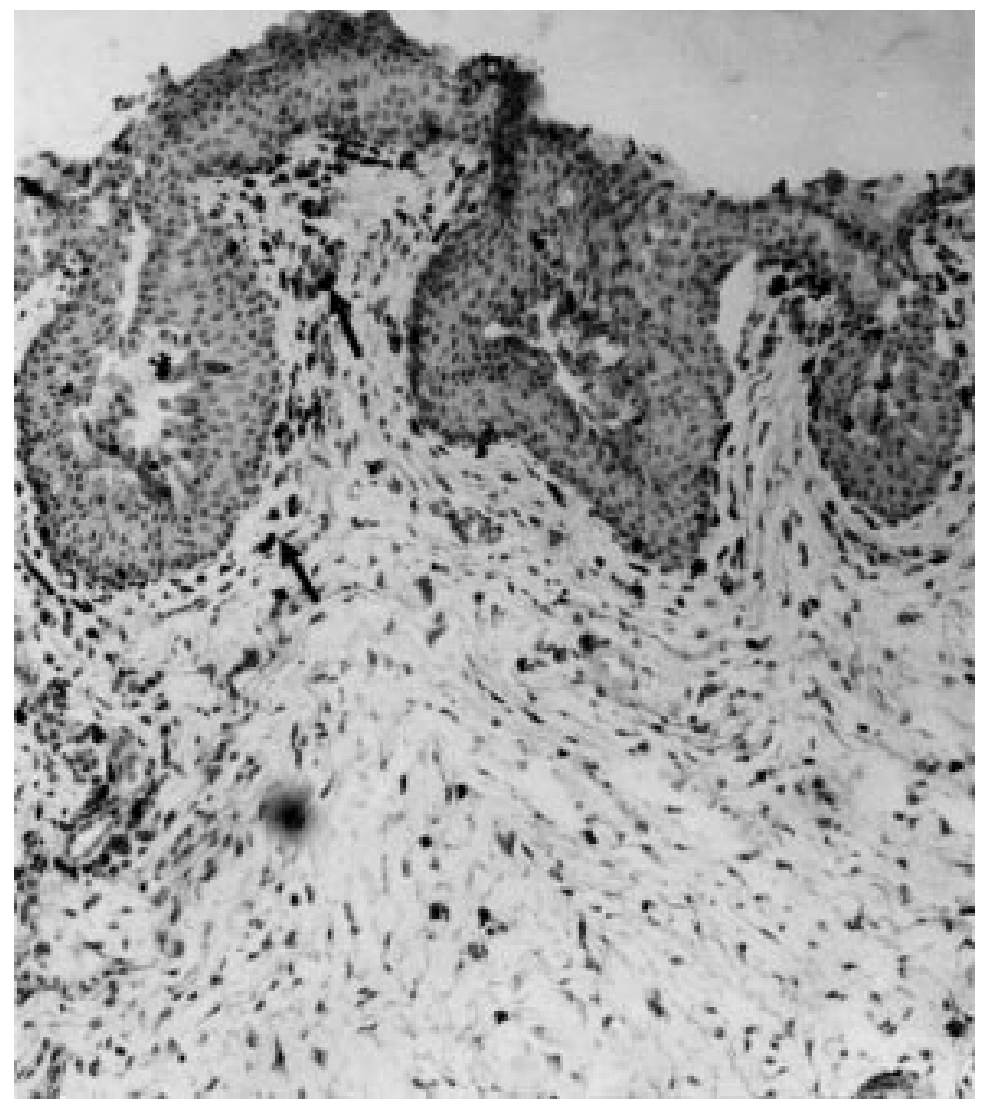

Figure 2 Normal conjunctiva. Immunohistochemical staining for lymphocyte function associated antigen-1 (LFA-1). LFA-1 is expressed on mononuclear cells (arrows) (three step avidin/biotin peroxidase labelled complex procedure; $\times 200)$. consist of single chain molecules with a variable number of immunoglobulin-like, extracellular domains. Intercellular adhesion molecule-1 (ICAM-1), intercellular adhesion molecule-3 (ICAM-3), and vascular cell adhesion molecule-1 (VCAM-1) are members of the immunoglobulin gene superfamily. The selectins are a group of transmembrane glycoproteins characterised by an $\mathrm{N}$ terminal lectin domain, an epidermal growth factor domain, and a series of complement regulatory domains. E-selectin (endothelial leucocyte adhesion molecule-1, ELAM-1) is a member of this group. The following receptor-counter receptor relations have been confirmed: LFA-1 to ICAM-1; VCAM-1 to VLA-4; and ELAM-1 to sialyl Lewis $\mathrm{X}$ which is found on neutrophil and lymphocyte cell surfaces. ${ }^{4-6}$

The purpose of this study was to determine the in situ expression of adhesion molecules in conjunctival biopsy specimens from patients with active VKC and to relate the observations to the inflammatory cell infiltrate.

\section{Patients and methods}

PATIENTS

Seven consecutive patients with severe active VKC seen at the outpatient clinic of King Abdulaziz University Hospital were included in this study. All the patients were males and their ages ranged from 7 to 15 years, with a mean age of 11 years. The symptoms mentioned by all the patients were itching, redness, photophobia, and tearing. Each patient underwent complete ophthalmic examination, and the corneal and conjunctival changes were noted and recorded. All patients had the palpebral form of the disease characterised by the presence of giant polygonal flat topped cobblestone papillae affecting the upper palpebral conjunctiva. Upper palpebral conjunctival biopsy specimens were obtained from both eyes of each patient. None of the patients was on topical therapy before obtaining the biopsy. In addition, four conjunctival biopsy specimens were obtained from patients undergoing cataract extraction or operations for retinal detachment without obvious inflammation and these served as controls. The controls were from the same age group.

This study was approved by the Research Center, College of Medicine, King Saud University and the patients admitted to the study gave their informed consent.

IMMUNOHISTOCHEMICAL STAINING

The conjunctival biopsy specimens were immediately snap frozen in Tissue-Tek optimum cutting temperature (OCT) compound (Miles Laboratories, IN, USA) and maintained at $-80^{\circ} \mathrm{C}$ until use. Cryostat sections were cut and stained with haematoxylin and eosin for routine histology. For immunohistochemistry, $5 \mu \mathrm{m}$ serially cut cryostat sections were dried overnight at room temperature, fixed in absolute acetone for 10 minutes, and stained with a three step avidin/biotin peroxidase labelled complex procedure. Rehydrated slides were incubated for 30 minutes with the mouse monoclonal antibodies listed in Table 1 which 


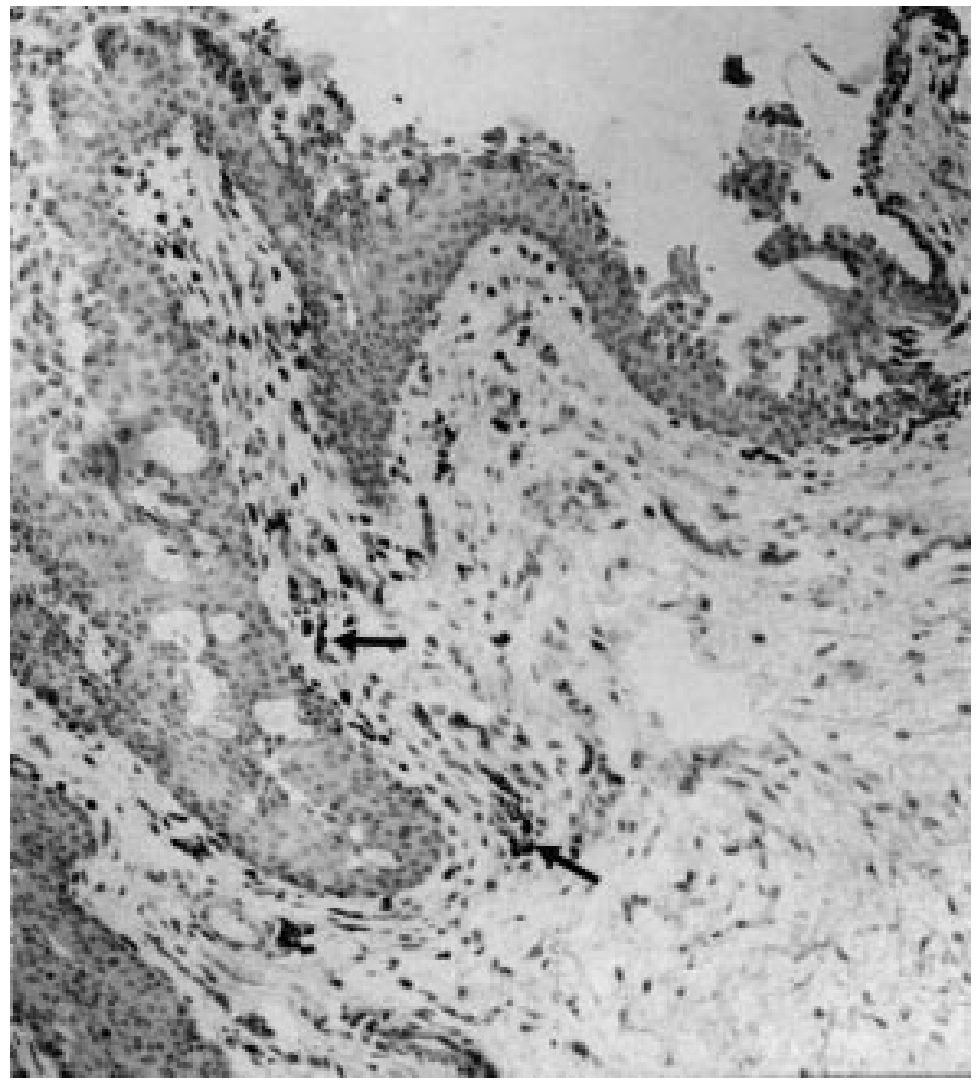

Figure 3 Normal conjunctiva. Immunohistochemical staining for intercellular adhesion molecule-3 (ICAM-3). ICAM-3 is expressed on mononuclear cells (arrows) (three step avidin/biotin peroxidase labelled complex procedure; $\times 200)$.

were diluted to an optimum concentration. The secondary and tertiary antibodies consisted of biotin conjugated rabbit antimouse immunoglobulin and the avidin/biotin peroxidase labelled complex, respectively, which were both purchased from Dakopatts A/S (Copenhagen, Denmark). All incubations were carried out for 30 minutes at room temperature, then washed in three changes of phosphate buffered saline at $\mathrm{pH} 7.2$ for 15 minutes. The reaction product was visualised by incubation for 10 minutes in $0.05 \mathrm{M}$ acetate buffer at $\mathrm{pH} 4.9$, containing $0.05 \%$ 3-amino-9-ethyl-carbazole and $0.01 \%$ hydrogen peroxide, resulting in bright red immunoreactive sites. The slides were faintly counterstained with Harris haematoxylin. Finally, the sections were rinsed with distilled water and coverslipped with glycerol. Controls, which were invariably negative, con-

Table 2 Number of immune cells in VKC and control specimens (mean (SD))

\begin{tabular}{llll}
\hline Cell type & Control $(n=4)$ & VKC $(n=14)$ & $p$ Value \\
\hline ICAM-1 (CD54) & 0 & $34.7(9.6)$ & - \\
ICAM-3 (CD50) & $19.0(4.7)$ & $76.4(11.4)$ & $<0.0001$ \\
LFA-1 $\alpha$ chain (CD11a) & $15.0(2.6)$ & $87.9(13.1)$ & $<0.0001$ \\
LFA-1 $\beta$ chain (CD18) & $14.8(1.7)$ & $90.5(24.9)$ & $<0.0001$ \\
VLA-4 (CD49D) & $3.8(1.7)$ & $21.6(7.2)$ & 0.0001 \\
HLA-DR & $17.3(2.2)$ & $75.3(13.0)$ & $<0.0001$ \\
T helper/inducer cells (OKT4-Leu3a) & $14.5(4.7)$ & $43.7(13.9)$ & 0.0004 \\
T cytotoxic/suppressor cells (OKT8) & $14.3(3.9)$ & $16.2(5.8)$ & $0.27(\mathrm{NS})$ \\
B cells (L26) & $17.8(7.8)$ & $32.6(17.0)$ & $0.059(\mathrm{NS})$ \\
Macrophages (KP1) & $19.3(4.3)$ & $27.9(8.9)$ & 0.04 \\
\hline
\end{tabular}

VKC = vernal keratoconjunctivitis; ICAM-1 = intercellular adhesion molecule-1; ICAM-3 = intercellular adhesion molecule-3; LFA = lymphocyte function antigen-1; VLA- $4=$ very late activation antigen- 4

$\mathrm{NS}=$ not significant sisted of omission of primary or secondary antibody and use of chromogen alone.

Cells were counted in five representative fields. We used an eyepiece calibrated grid with $\times 25$ magnification. With this magnification and calibration we counted the cells present in an area of $0.155 \times 0.155 \mathrm{~mm}$. Means (SD) were calculated for each cell type in VKC and control specimens. The $t$ test for independent groups was used to analyse the statistical significance of differences between mean values. The differences were considered significant if $\mathrm{p}$ value was $<0.05$.

\section{Results}

LIGHT MICROSCOPY

All biopsies showed comparable changes characteristic of the disease. The conjunctival surface appeared irregular and thrown into folds covered by a well preserved hyperplastic epithelium showing reticular acanthosis and infiltrated by mononuclear cells, eosinophils, and mast cells. The density of the infiltrating cells was lower in the epithelium than in the stroma. The underlying stroma showed oedema and a heavy inflammatory infiltrate that was concentrated just beneath the epithelium and in the perivascular areas. The stromal inflammatory infiltrate was organised as a diffuse infiltrate and as small lymphoid follicles without reactive centres. The diffuse infiltrate consisted of mononuclear cells, eosinophils, and mast cells. The stromal blood vessels were lined by prominent endothelium and surrounded by inflammatory cells.

\section{IMMUNOHISTOCHEMISTRY}

Normal conjunctival biopsy specimens

Conjunctival epithelial cells were negative for HLA-DR antigens. HLA-DR ${ }^{+}$mononuclear cell were noted in the basal layers of the epithelium and in the superficial stroma just beneath the epithelium. Some of the intraepithelial cells were dendritic Langerhans cells. The vascular endothelial cells expressed HLA-DR antigens. $\mathrm{KP}^{+}$macrophages were noted in the basal epithelial layers and in the superficial stroma. $T$ lymphocytes were present in the basal epithelium and in the superficial stroma. In the epithelium $\mathrm{OKT}^{+}$cells predominated over OKT4-Leu $3 \mathrm{a}^{+}$cells, whereas in the stroma OKT4-Leu $3 \mathrm{a}^{+}$cells outnumbered $\mathrm{OKT}^{+}$ cells. $\mathrm{L}^{+} 6^{+} \mathrm{B}$ lymphocytes were noted in the superficial stroma.

Weak ICAM-1 expression was noted only on the vascular endothelium mainly in the superficial stroma (Fig 1). LFA-1 (Fig 2) and ICAM-3 (Fig 3) were expressed on mononuclear cells in the basal epithelium and in the superficial stroma. VLA-4 was found only on few mononuclear cells in the superficial stroma. ELAM-1 and VCAM-1 expression was not detected.

\section{Conjunctival specimens from VKC patients}

Similar findings were noted in all biopsy specimens. The density of the inflammatory infiltrate in the conjunctival biopsy specimens from VKC patients was greater than that in normal 
Table 3 Distribution of adhesion molecules in normal conjunctiva and conjunctiva from patients with VKC

\begin{tabular}{|c|c|c|c|c|c|c|}
\hline \multirow{2}{*}{$\begin{array}{l}\text { Adhesion } \\
\text { molecule }\end{array}$} & \multicolumn{3}{|c|}{ Normal conjunctiva $(n=4)$} & \multicolumn{3}{|c|}{$V K C(n=14)$} \\
\hline & $E P C$ & $V E C$ & $M C$ & $E P C$ & $V E C$ & $M C$ \\
\hline ICAM-1 & - & + & - & $+++^{\star}$ & +++ & ++ \\
\hline ICAM-3 & - & - & + & - & - & +++ \\
\hline LFA-1 & - & - & + & - & - & +++ \\
\hline VLA-4 & - & - & + & - & - & ++ \\
\hline VCAM-1 & - & - & - & - & + & - \\
\hline ELAM-1 & - & - & - & - & + & - \\
\hline
\end{tabular}

VKC $=$ vernal keratoconjunctivitis $; \mathrm{EPC}=$ epithelial cells; $\mathrm{VEC}=$ vascular endothelial cells; $\mathrm{MC}$ = mononuclear cells; ICAM-1 = intercellular adhesion molecule- 1 ; ICAM-3 = intercellular adhesion molecule-3; LFA-1 = lymphocyte function associated antigen-1; VLA-4 = very late activation antigen-4; VCAM-1 = vascular cell adhesion molecule- 1 ; ELAM-1 = endothelial leucocyte adhesion molecule-1.

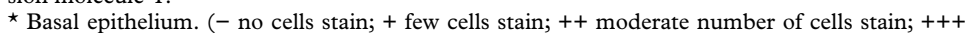
nearly all cells stain).

conjunctiva. The results are shown in detail in Table 2, and a summary is given in Table 3.

The epithelium lacked HLA-DR expression and was infiltrated by large numbers of HLA-DR ${ }^{+}$cells, including dendritic Langerhans cells, $\mathrm{KP}^{+}$macrophages, OKT4-Leu3a ${ }^{+}$ helper/inducer $\mathrm{T}$ lymphocytes, $\mathrm{OKT}^{+}$ suppressor/cytotoxic $\mathrm{T}$ lymphocytes, and $\mathrm{L}^{2} 6^{+}$ B lymphocytes. The stroma showed a dense inflammatory infiltrate which was organised as a diffuse infiltrate and as small lymphoid follicles without reactive centres. The infiltrate was most intense in the area just underneath the



Figure 4 Vernal keratoconjunctivitis. Immunohistochemical staining for intercellular adhesion molecule-1 (ICAM-1). The basal epithelial cells (long arrow), vascular endothelium (short arrow), and infiltrating mononuclear cells (arrowhead) expres ICAM-1 (three step avidin/biotin peroxidase labelled complex procedure; $\times 450$ ). epithelium and in the perivascular areas. The diffuse infiltrate was mixed in composition and consisted of OKT4-Leu3a ${ }^{+}$helper/inducer T lymphocytes, $\mathrm{OKT}^{+}$suppressor/cytotoxic $\mathrm{T}$ lymphocytes, $\mathrm{KP}^{+}$macrophages, $\mathrm{L}^{+} 6^{+} \mathrm{B}$ lymphocytes, plasma cells, eosinophils, and mast cells. The majority of the mononuclear cells were HLA-DR ${ }^{+}$. In all specimens OKT4Leu3 $\mathrm{a}^{+}$helper/inducer $\mathrm{T}$ lymphocytes predominated over $\mathrm{OKT}^{+}$suppressor/cytotoxic $\mathrm{T}$ lymphocytes. The lymphoid follicles consisted of $\mathrm{L}^{2} 6^{+}$HLA-DR ${ }^{+}$B lymphocytes. Few $\mathrm{T}$ lymphocytes were observed which were mostly OKT4-Leu3a ${ }^{+}$helper/inducer T cells. VKC specimens showed statistically significant higher counts than control specimens for HLA-DR ${ }^{+}$, OKT4-Leu3a ${ }^{+}$, and $\mathrm{KP}^{+}$cells. Statistically insignificant higher numbers of $\mathrm{OKT}_{8}^{+}$, and $\mathrm{L}^{2} 6^{+}$cells were noted in VKC specimens compared with control specimens.

All the specimens showed strong ICAM-1 expression on the basal layer of the conjunctival epithelium and on the vascular endothelium of all blood vessels. Furthermore, mononuclear cells in the diffuse stromal infiltrate, and lymphocytes in the lymphoid follicles expressed ICAM-1 (Fig 4). LFA-1 (Fig 5) and ICAM-3 (Fig 6) were expressed on the majority of epithelial and stromal mononuclear cells and on the majority of lymphocytes in the lymphoid follicles. Mononuclear cells in the diffuse stromal infiltrate expressed VLA-4. VLA-4 was not expressed on the lymphocytes in the lymphoid follicles. Compared with controls, VKC specimens showed statistically significant more ICAM $-3^{+}$, LFA $-1^{+}$, and VLA $-4^{+}$ cells. Weak expression of ELAM-1 (Fig 7) and VCAM-1 (Fig 8) was noted on the vascular endothelium mainly in the superficial stroma.

\section{Discussion}

In the normal conjunctiva, ICAM-1 was primarily confined to a low level of cell surface expression on the vascular endothelium. Our observations were consistent with previous reports that ICAM-1 was expressed only on the vascular endothelial cells in normal conjunctiva, ${ }^{7}$ normal skin, ${ }^{8}$ and normal mucosa of the colon and small intestine. ${ }^{9}$ Compared with normal conjunctiva, the conjunctiva from patients with active VKC, showed strong expression of ICAM-1 on the basal epithelial cells and vascular endothelial cells. Furthermore, stromal mononuclear cells were ICAM-1 positive. ICAM-1 mediates the adhesion of $\mathrm{T}$ cells to antigen presenting cells or target cells and is also involved in $\mathrm{T}$ cell to $\mathrm{T}$ cell and T cell to B cell interactions. Binding of ICAM-1 has a costimulatory effect on $\mathrm{T}$ cell activation. In addition, ICAM-1 is important in the adhesion of monocytes, lymphocytes, and neutrophils to activated endothelium. ${ }^{3}{ }^{10}$ It has been shown that expression of ICAM-1 can be induced or upregulated severalfold by inflammatory cytokines including interferon gamma (IFN- $\gamma$ ), interleukin $1 \beta$ (IL-1 $\beta$ ), and tumour necrosis factor $\alpha(\mathrm{TNF}-\alpha) \cdot{ }^{811-13}$ Similarly, ICAM-1 upregulation was notedin skin biopsies from patients with allergic 


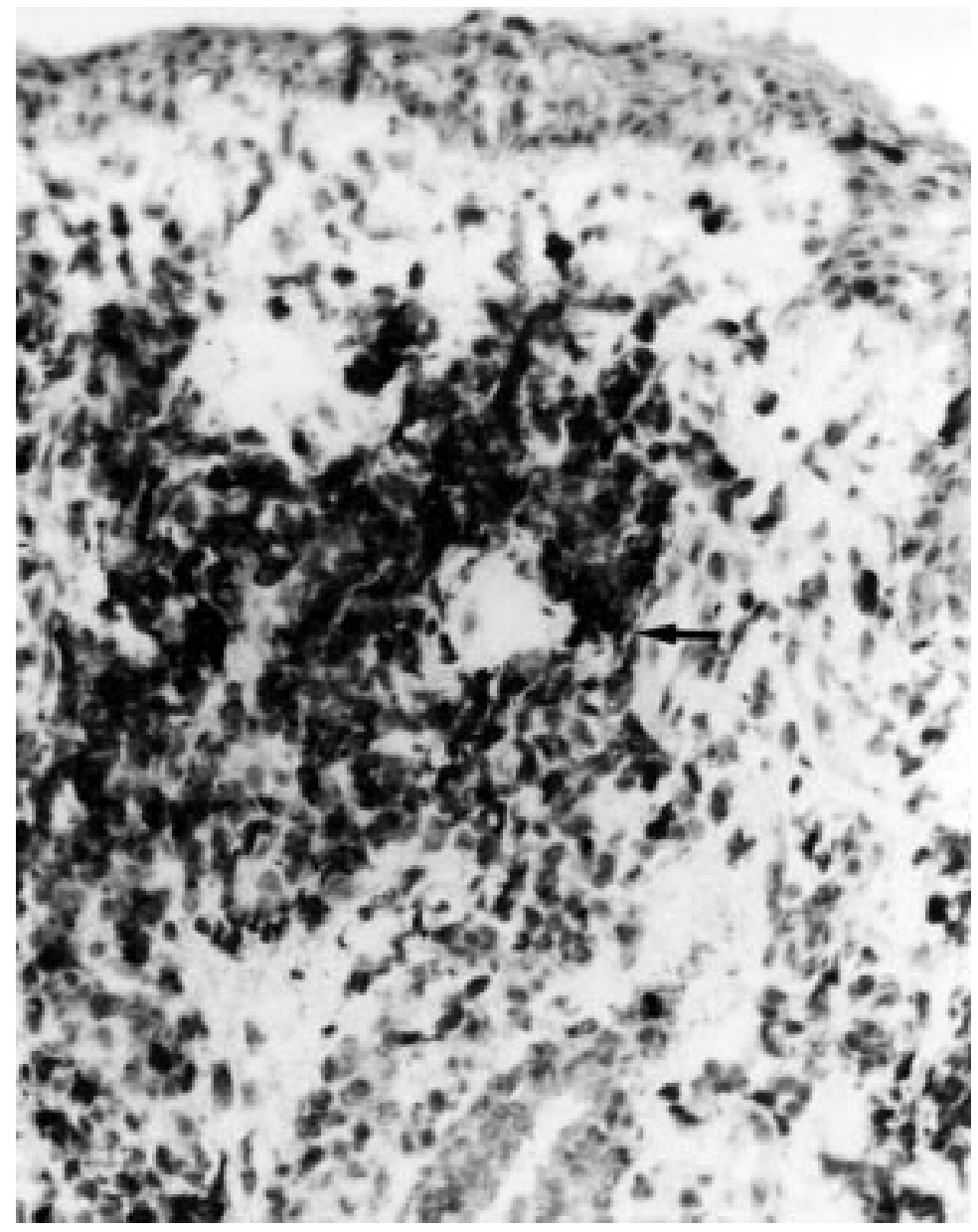

Figure 5 Vernal keratoconjunctivitis. Immunohistochemical staining for lymphocyte function associated antigen-1 (LFA-1). Infiltrating mononuclear cells express LFA-1 (arrow) (three step avidin/biotin peroxidase labelled complex procedure; $\times 280$ ).

dermatoses, ${ }^{8} 1415$ bronchial biopsies from patients with intrinsic and extrinsic asthma, ${ }^{1617}$ and nasal mucosal biopsies from patients with allergic rhinitis. ${ }^{18} 19$

LFA-1 which interacts with ICAM-1 was strongly expressed on the majority of inflammatory mononuclear cells in the conjunctival epithelium and stroma in VKC. These mononuclear cells were often closely apposed to ICAM-1 positive vascular endothelial cells and epithelial cells. ICAM-1 plays a critical role in leucocyte adhesion by acting as the ligand for LFA-1 constitutively expressed by lymphocytes, neutrophils, monocytes, and macrophages. ${ }^{3021}$ Our results suggest that the interaction of ICAM-1 with LFA-1 may be crucial for the migration of inflammatory cells in the conjunctival stroma and epithelium and the development of conjunctival inflammation in VKC. Moreover, ICAM-1 expression by basal epithelial cells may be an important initiator of epithelial cell-lymphocyte interactions by means of LFA-1/ICAM-1 interactions.

In sharp contrast with our results for ICAM-1, we found that there was no expression of HLA-DR antigens by the epithelial cells. This shows that the expressions of ICAM-1 and HLA-DR are probably regulated differently. Similar differences between the expression of ICAM-1 and HLA-DR antigens on epithelial cells were previously shown in some inflammatory dermatoses,${ }^{814}{ }^{15}$ in which keratinocytes expressed ICAM-1 but no HLA-DR antigens. It is well known that the expression of HLA-DR antigens requires stimulation with IFN- $\gamma^{822}{ }^{23}$ produced by activated $\mathrm{T}$ cells. Our findings suggest, therefore, that this immunoregulatory cytokine may not play a major role in the pathophysiology of VKC. This is despite the fact that a high density of activated $T$ cells expressing HLA-DR antigens predominantly of the helper/inducer subset have been observed in the conjunctival epithelial and stromal infiltrate in VKC. Two different types of helper/inducer $\mathrm{T}$ cell clones have been identified. The TH1 cells secrete IL- 2 , IFN- $\gamma$, and TNF while TH 2 cells secrete IL-3, IL-4, IL-5, IL-6, and IL-10. The TH1 responses are characterised by strong cell mediated immunity and often only a modest humoral response. In contrast, $\mathrm{TH} 2$ responses are usually associated with high titre antibody responses, but poor delayed type hypersensitivity reactions. ${ }^{24}$ Thus, it is proposed that in patients with VKC, the putative antigens may predominantly stimulate $\mathrm{TH} 2$ cells which do not produce IFN- $\gamma$, an important inducer of HLA-DR antigens. IL-3 and IL-4, products of $\mathrm{TH} 2$ cells, regulate the proliferation of mast cells. ${ }^{25}$ IL-4 was also shown to induce IgE switching and IgE synthesis by B cells. ${ }^{27}$ Our results for HLA-DR when taken into consideration with those for ICAM-1 imply that TNF- $\alpha$ and IL- $1 \beta$ rather than IFN- $\gamma$ are among the more significant immune associated inflammatory mediators in VKC. This view is strengthened by the fact that macrophages presumably capable of producing $\mathrm{TNF}-\alpha$ and IL- $1^{28}$ are present in abundance in both the conjunctival epithelium and stroma in VKC. In addition, it was shown that mast cell degranulation results in TNF- $\alpha$ and IL-1 release. ${ }^{29} 30$

ICAM-3 was expressed on the majority of mononuclear cells infiltrating the conjunctival epithelium and stroma in VKC. ICAM-3 is constitutively expressed on monocytes, granulocytes, and the majority of lymphocytes, but not on normal or activated endothelial cells. ${ }^{31}$ Quantitative functional data suggested that ICAM-3 is the major counter receptor for LFA-1 on all resting leucocytes. ${ }^{32}$ Recent data implicate ICAM-3 as an important molecule involved in the activation of resting $T$ cells. It is able to induce homotypic lymphocyte aggregation, both by LFA-1/ICAM-3 dependent and independent pathways, and is costimulatory for T cells. It has been postulated that ICAM-3 could be the initial ligand for LFA-1 during antigen induced leucocyte interactions. ${ }^{33}$

In the normal conjunctiva the expression of ELAM-1 and VCAM-1 was virtually nonexistent. This corresponds with results obtained in the normal skin. ${ }^{34}$ In contrast, there was a weak expression of ELAM-1 and VCAM-1 on the vascular endothelium in VKC. ELAM-1 and VCAM-1 are induced on endothelial cells by IL-I $\beta$ and TNF- $\alpha .{ }^{35}{ }^{36}$ In addition, IL-4 was found to be a selective stimulus for upregulating the expression of 




Figure 6 Vernal keratoconjunctivitis. Immunohistochemical straining for intercellular adhesion molecule-3 (ICAM-3). Infiltrating mononuclear cells express ICAM-3 (arrow) (three step avidin/biotin peroxidase labelled complex procedure; $\times 280$ ).
VCAM-1 on endothelial cells. ${ }^{37}$. Upon stimulation, mast cells release factors, including TNF- $\alpha$, IL- 1 , and IL- $4{ }^{29}{ }^{30}$ which can modulate adhesion molecules on endothelial cells. Sialyl Lewis $\mathrm{X}$ is a ligand for ELAM-1 and it forms a carbohydrate side chain on L-selectin, found on neutrophil and lymphocyte cell surfaces. L-selectin may, therefore, present sialyl Lewis $\mathrm{X}$ to ELAM-1 expressed on activated vascular endothelium. ${ }^{5}$ ELAM-1 mediates adherence of neutrophils, monocytes, and some memory $\mathrm{T}$ cells to vascular endothelium in the early phase of inflammatory reactions, ${ }^{35}{ }^{38-40}$ hence it is important in the regulation of inflammatory and immunological events at the vessel wall. In the present study, VLA-4 was expressed on mononuclear cells in the stromal infiltrate. VLA-4 expressed on eosinophils, monocytes, and lymphocytes is a ligand for VCAM- $1 .^{41}$ Because VLA-4 is expressed on eosinophils and not on neutrophils, VCAM-1 is postulated to mediate selective eosinophil recruitment. ${ }^{19} 42$ Blocking VCAM-1 with a specific antibody was extremely effective in inhibiting eosinophil adherence in vitro but had no effect on neutrophil adherence, supporting the importance of VCAM-1 in the migration of eosinophils but not neutrophils. ${ }^{42}$ Ebisawa and associates $^{43}$ have shown that the initial attachment of eosinophils to IL-1 $\beta$ activated endothelial cells involves VCAM-1, ELAM-1, and ICAM-1. However, the subsequent transendothelial migration process relies heavily on the expression of CD11/CD18 on eosinophilic granulocytes and of ICAM-1 on endothelial cells. Similarly, a significant expression of ELAM-1, and VCAM-1 was demonstrated in allergic diseases as intrinsic and extrinsic asthma, ${ }^{16}{ }^{17}$ atopic dermatitis, ${ }^{34}$ and allergic rhinitis. ${ }^{18} 19$

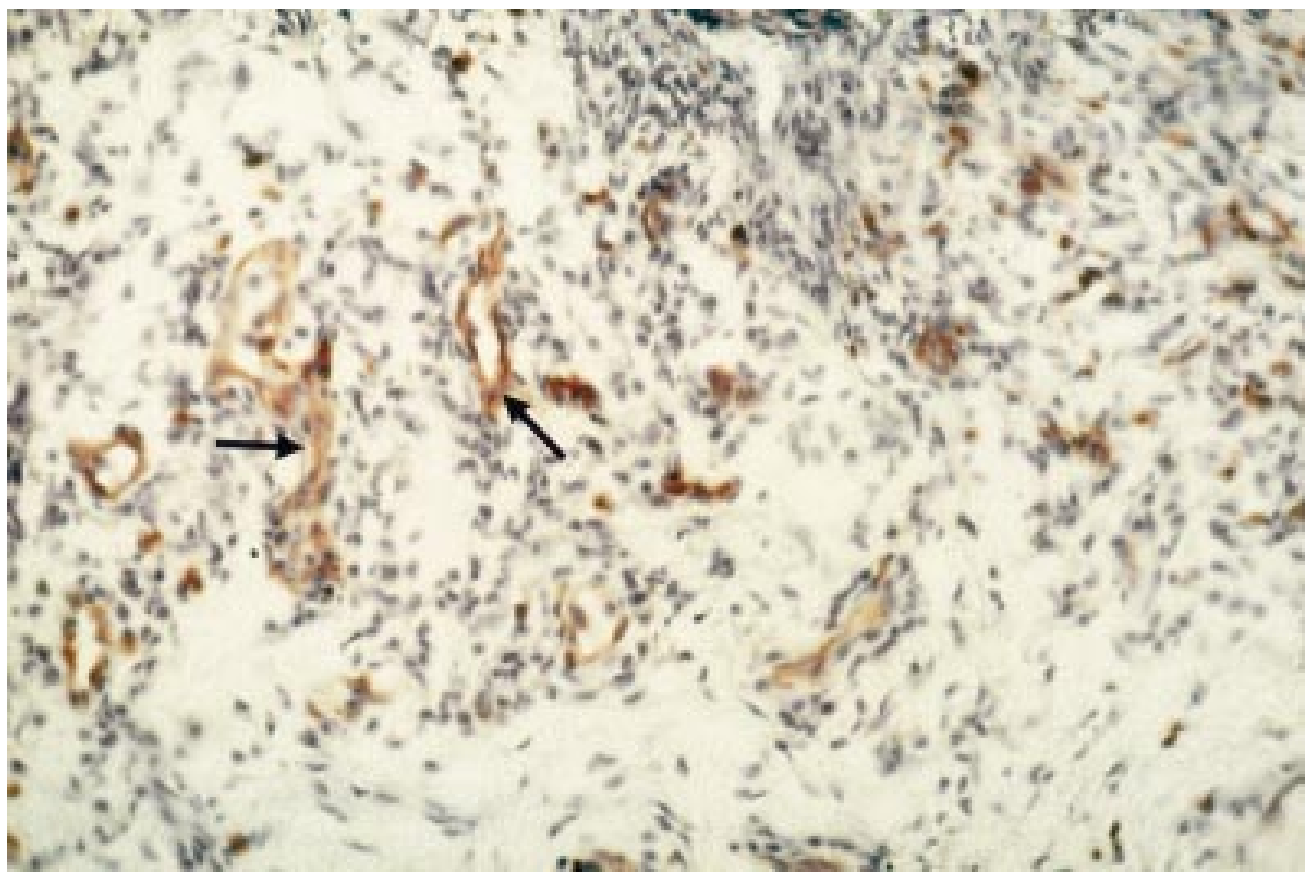

Figure 7 Vernal keratoconjunctivitis. Immunohistochemical staining for endothelial leucocyte adhesion molecule-1 (ELAM-1). ELAM-1 is expressed on the vascular endothelium (arrows) (three step avidin/biotin peroxidase labelled complex procedure; $\times 180$ ). 




Figure 8 Vernal keratoconjunctivitis. Immunohistochemical staining for vascular cell adhesion molecule-1 (VCAM-1). VCAM-1 is expressed on the vascular endothelium (arrows) (three step avidin/biotin peroxidase labelled complex procedure $\times 180$ ).

In conclusion, increased expression of adhesion molecules promotes the recruitment of inflammatory cells through blood vessels and the cell interactions between lymphocytes and antigen presenting cells, among lymphocytes, and between lymphocytes and epithelial cells, thereby sustaining the immunoinflammatory process in VKC. Interfering with such adhesive interactions with monoclonal antibodies directed against adhesion molecules may provide new therapeutic modalities in VKC.

The authors thank Ms Christel Van den Broeck and Mr Hank Cooper for technical assistance, Ms Connie B Unisa for her secretarial work, and $\mathrm{Mr}$ Amir Marzouk for statistical assistance.

1 Abu El-Asrar AM, Van den Oord JJ, Geboes K, Missotten L, Emarah MH, Desmet V. Immunopathological study of vernal keratoconjunctivitis. Graefes Arch Clin Exp Ophthalmol 1989;227:374-9.

2 Abu El-Asrar AM, Tabbara KF, Geboes K. Missotten L, Desmet V. An immunohistochemical study of topical
cyclosporine in vernal keratoconjunctivitis. Am $\mathscr{f}$ Ophthalmol 1996;121:156-61.

3 Springer TA. Adhesion receptors of the immune system. Nature 1990;346:425-34.

4 Pilewski JM, Albelda SM. Adhesion molecules in the lung. An overview. Am Rev Respir Dis 1993;148:531-7.

5 Smith CH, Barkor JNWN, Lee TH. Adhesion molecules in allergic inflammation. Am Rev Respir Dis 1993;148:575-8.

6 Hamacher J, Schaberg T. Adhesion molecules in lung Hamacher J, Schaberg T. Adhesion mol
diseases. Review. Lung 1994;172:189-213.

7 Vorkouf M, Duncker G, Nolle B, Sterry W. Adhesion molecules in normal human conjunctiva. An immunohistochemical study using monoclonal antibodies. Graefes Arch Clin Exp Ophthalmol 1993;231:323-30.

8 Griffiths CEM, Voorhees JJ, Nickoloff BJ. Characterization of intercellular adhesion molecule-1 and HLA-DR expression in normal and inflamed skin: modulation by recombinant gamma interferon and tumor necrosis factor. f Am Acad Dermatol 1989;20:617-29.

9 Nakamura S, Ohtani H, Watanabe Y, Fukushima K, Matsumoto T, Kitano A, et al. In situ expression of cell adhesion molecules in inflammatory bowel disease. Evidence of immunologic activation of vascular endothelia cells. Lab Invest 1993;69:77-85.

10 Malizia G, Calabrese A, Cottone M, Raimondo M, Trejdosiewicz LK, Smart CJ, et al. Expression of leucocyte
adhesion molecules by mucosal mononuclear phagocytes in inflammatory bowel disease. Gastroenterology 1991;100: in inflam $150-9$.

11 Dustin ML, Springer TA. Lymphocyte function associated antigen-1 (LFA-1) interaction with intercellular adhesion molecule-1 (ICAM-1) is one of at least three mechanisms for lymphocyte adhesion to cultured endothelial cells. Cell Biol 1988;107:321-31.

12 Dustin ML, Rothlein R, Bhan AK, Dinarello CA, Springer TA. Induction by IL-1 and interferon, tissue distribution, biochemistry, and function of a natural adherence molecule (ICAM-1). F Immunol 1986;137:245-54.

13 Takahashi K, Takigawa M, Takashiba S, Nagai A, Miyamoto $\mathrm{M}$, Kurihara $\mathrm{H}$, et al. Role of cytokine in the induction of adhesion molecules on cultured human gingival fibroblasts. F Periodontol 1994;65:230-5.

14 Vejlsgaard GL, Ralfkiaer E, Avnstorp C, Czajkowski M, Marlin SD, Rothlein R. Kinetics and characterization of intercellular adhesion molecule-1 (ICAM-1) expression on keratinocytes in various inflammatory skin lesions and malignant cutaneous lymphomas. Am Acad Dermatol 1989; malignant cuta

15 Willis CM, Stephens CJM, Wilkinson JD. Selective expression of immune-associated surface antigens by keratinocytes in irritant contact dermitis. F Invest Dermatol 1991;96: 505-11.

16 Montefort S, Gratzion C, Goulding D, Polosa R. Haskard DO, Howarth PH, et al. Bronchial biopsy evidence for leukocyte infiltration and upregulation of leukocyteendothelial cell adhesion molecules 6 hours after local allergen challenge of sensitized asthmatic airways. 7 Clin Invest 1994;93:1411-21.

17 Bentley AM, Durham SR, Robinson DS, Menz G, Storz C, Cromwell $\mathrm{O}$, et al. Expression of endothelial and leukocyte adhesion molecules intercellular adhesion molecule-1, E-selectin, and vascular cell adhesion molecule-1 in the bronchial mucosa in steady-state and allergen-induced asthma. F Allergy Clin Immunol 1993;92:857-68.

18 Montefort S, Feather IH, Haskard DO, Lee TH, Holgate ST, Howarth PH. The expression of leukocyte-endothelial adhesion molecules is increased in perennial allergic rhiniadhesion molecules is increased in perennial
tis. Am 7 Respir Cell Mol Biol 1992;7:393-8.

19 Lee BJ, Naclerio RM, Bochner BS, Taylor RM, Lim MC, Baroody FM. Nasal challenge with allergen upregulates the local expression of vascular endothelial adhesion molecules. F Allergy Clin Immunol 1994;94:1006-16.

20 Springer TA. The sensation and regulation of interactions with the extracellular environment: the cell biology of lymphocyte adhesion receptors. Annu Rev Cell Biol 1990;6: 359-402.

21 Marlin SD, Springer TA. Purified intercellular adhesion molecule-1 (ICAM-1) is a ligand for lymphocyte function associated antigen-1 (LFA-1). Cell 1987;51:813-9.

22 Abu El-Asrar AM, Van den Oord JJ, Billiau A, Desmet V, Emarah $\mathrm{MH}$, Missotten L. Recombinant interferongamma induces HLA-DR expression on human corneal epithelial and endothelial cells in vitro: a preliminary report. Br f Ophthalmol 1989;73:587-90.

23 Abu El-Asrar AM, Maimone D, Morse PH, Lascola C, Reder AT. Interferon- $\gamma$ and tumor necrosis factor induce expression of major histocompatibility complex antigens on rat retinal astrocytes. Br f Ophthalmol 1991;75:473-5.

24 Mosmann TR, Coffman RL. TH1 and TH2 cells: different patterns of lymphokine secretion lead to different functional properties. Annu Rev Immunol 1989;7:145-73. 
25 Abe T, Ochiai H, Mimamishima Y, Nawa Y. Induction of intestinal mastocytosis in nude mice by repeated injection of interl $356-61$.

26 Lee F, Yokota T, Otsuka T, Meyerson P, Villaret D, Coffiman $\mathrm{R}$, et al. Isolation and characterization of a mouse interleukin cDNA clone that expresses B cell stimulatory factor 1 activities and T-cell- and mast-cell stimulating activities. Proc Natl Acad Sci USA 1986;83:2061-9.

27 Mills FC, Thyphronitis G, Finkelman FD, Max EE. Is mu-epsilon isotype switch in IL-4 treated human lymphoblastoid cells. Evidence for a sequential switch. F Immunol 1992;149:1075-85

28 Sisson SD, Dinarello CA. Production of interleukin-1 alpha, interleukin-1 beta and tumor necrosis factor by human mononuclear cells stimulated with granulocytemacrophage colony-stimulating factor. Blood 1988;72: macrophage

29 Kelin LM, Lavker RM, Matis WL, Murphy GF. Degranulation of human mast cell induces an endothelial antigen tion of human mast cell induces an endothelial antigen 1989;86:8972-6.

30 Burd PR, Rogers HW, Gordon JR, Martin CA, Jayaraman S Wilson SD, et al. Interleukin 3-dependent and -independent mast cells stimulated with $\mathrm{IgE}$ and antigen express multiple cytokines. F Exp Med 1989;170:245-57.

31 Cordell JL, Pulford K, Turley H, Jones M, Micklem K, Doussis IA, et al. Cellular distribution of human leukocyte adhesion molecule ICAM-3. F Clin Pathol 1994;47:143-7.

32 De Fougerolles AR, Springer TA. Intercellular adhesion molecule 3, a third adhesion counter-receptor for lymphocyte function-associated molecule

33 Gorski A. The role of cell adhesion molecules in immunopathology. Immunol Today 1994;15:251-5.

34 Wakita H, Sakamoto T, Tokura Y, Takigawa M. E-Selectin and vascular cell adhesion molecule- 1 as critical adhesion molecules for infiltration of T lymphocytes and eosinophils in atopic dermatitis. 7 Cutan Pathol 1994;21:33-9.
35 Bevilacqua MP, Stengelin S, Gimbrone Jr MA, Seed B. Endothelial leukocyte adhesion molecule-1: an inducible
receptor for neutrophils related to complement regulatory receptor for neutrophils related to complement

36 Osborn L, Hessian C, Tizard R, Vasallo C, Luhowskyi S, Chi-Rosso G, et al. Direct expression cloning of vascular cell adhesion molecule-1, a cytokine-induced endothelial protein that binds to lymphocytes. Cell 1989;59:1203-11.

37 Thornhill MH, Wellicome SM, Mahiouz DL, Lanchbury JS, Kyan-Auny U, Haskard DO. Tumor necrosis factor combines with IL-4 or IFN-gamma to selectively enhance endothelial cell adhesiveness for $\mathrm{T}$ cells. The contribution independent binding mechanisms. F Immunol 1991;146: 592-8.

38 Picker LJ, Kishimoto TK, Smith CW, Warnock RA, Butcher EC. ELAM-1 is an adhesion molecule for skin-homing T-cells. Nature 1991;349:796-9.

39 Shimizu Y, Shaw S, Graber N, Venkat Gopal T, Horgan KJ, Van Seventer GA, et al. Activation independent binding of hum Seventer GA, et al. Activation independent binding of Nature 1991;349:799-802.

40 Bevilacqua MP, Nelson RM. Selectins. F Clin Invest 1993;91:379-87.

41 Elices MJ, Osborn L, Takada Y, Crouse C, Luhowskyj S, Hemier ME, et al. VCAM-1 on activated endothelium interacts with the leukocyte integrin VLA-4 at a site distinct from the VLA-4/Fibronectin binding site. Cell 1990;60:577-84

42 Walsh GM, Mermod JJ, Hartness A, Kay AB, Wardlaw AJ. Human eosinophil, but not neutrophil, adherence to IL-1 stimulated human umbilical vascular endothelial cells is very late antigen-4 dependent. 7 Immunol 1991;146:341923.

43 Ebisawa M, Bochner BS, Georas SN, Schleimer RP. Eosinophil transendothelial migration induced by cytokines. I Role of endothelial and eosinophil adhesion molecules in IL-1 beta-induced transendothelial migration. $\mathcal{f}$ Immunol 1992;149:4021-8. 